DE DE GRUYTER

OPEN

Polish Cartographical Review

Vol. 48, 2016, no. 3, pp. 91-100

DOI: $10.1515 /$ pcr-2016-0011

MAREK BARANOWSKI

Institute of Geodesy and Cartography

Marek.Baranowski@igik.edu.pl

DARIUSZ GOTLIB, ROBERT OLSZEWSKI

Warsaw University of Technology, Department of Cartography

d.gotlib@gik.pw.edu.pl, r.olszewski@gik.pw.edu.pl

\title{
Properties of cartographic modelling under contemporary definitions of a map
}

\begin{abstract}
The identity of cartography is determined by the manner of defining and interpreting the concept of "map". However, the term has not been unequivocally articulated as yet. There are many different definitions of maps available in literature - from those viewing map as a scaled-down, planar, graphic representation of geographical space, to those that equate a map to a specific model that is independent of the form of its presentation. Interestingly enough, the basis of such universal treatment of the map concept can be found already in the scientific works from the 1960s. Although contemporary definitions do not limit a map to a single form of presentation, such over-simplification still persists.

The issue has become very relevant given the rapidly increasing number of diverse geospatial applications designed to access spatial data and present it in diverse forms. So far, however, there are no clear rules for categorizing a given representation as cartographic or non-cartographic. And this often gives rise to various misconceptions, e.g. regarding the role and responsibilities of cartography as science and practical activity.

According to the authors of the article, a map is an ordered informational structure shaped by the years of practical experience and research in the field of cartography. Map arising in the process of cartographic modelling is understood as one of many possible models of the portrayed space. The model is formed in the course of thought processes, including abstraction and generalization in particular. Creation of the model involves the use of symbolism that can be decoded by the recipient. This does not mean, however, that the process of symbolization is limited exclusively to graphical representations. Map is also a tool for presenting spatial information in a visual, digital or tactile way. Therefore, the essence of map is determined by its "model" nature rather than the format of the cartographic message.

The authors have assumed that map is formed in the process of cartographic modelling and certain properties of the process can be defined, that distinguish it from other methods of spatial modelling. The properties recognized as characteristic for cartographic modelling include space portraying that enables identification of types of objects and phenomena, describing spatial relationships between objects, as well as their positioning in the applied reference system. In the authors' opinion, properties of cartographic modelling include also the intentional application of a specific level of generalization determined by the objective of the map, aware authorship of the message, unambiguity of communication and symbolization based on knowledge. The proposed approach should facilitate the classification of different products designed to represent space.
\end{abstract}

Keywords: cartographic modelling, definition of a map, theory of cartography, model of space, geoinformation

\section{Introduction}

Cartography is an area of human creative activity known for many centuries, although it was formally defined relatively recently. Thus it may seem that domain of cartography is universally known and defined unequivocally in the scientific community. But in fact, the only undisputable assertion is that the primary product of cartographic activity is a map. In 1995, the 10th ICA General Assembly in Barcelona adopted definition that characterizes cartography as a discipline dealing with the conception, production, dissemination and study of maps. Currently in use is its modified version sounding as follows: "Cartography is a discipline dealing with the art, science and technology of making and using maps (source: ICA, http://icaci.org/ mission/)".

Both in theory and in practice, we may come across many different ways of defining the term 
"map". Some definitions are no longer valid, others are ambiguous or incomplete, and a few seem to be completely wrong. This is because, among other things, new tools were put at the cartographer' disposal within the last 30 years, while the development of diverse technologies and evolving needs of users have led to the demand for new products portraying geographic space. Could these products be still called maps? And if not all of them, which ones can? Furthermore, is there a method allowing to categorize them appropriately?

Since updating the definition of cartography is one of the objectives of the Strategic Plan of the International Cartographic Association for the years 2011-2019, deliberations on the concept of map and cartography are currently well-timed.

The main purpose of this paper is to present results of the authors' research aiming to search for the unique properties of cartographic modelling. The authors conclude that it is cartographic modelling that forms a foundation of what makes cartography unique and shapes its identity.

\section{Some reflections on the basic concepts in cartography}

Presented below are some reflections derived from the author's analysis of concepts that are important in discussing the process of cartographic modelling. Given the size limitations of this paper, it was impossible to present here the full analysis of related literature. The volume of works published abroad on the subject is unusually extensive and analysis of such scope is typically presented in monographs. Therefore, this paper places greater emphasis on the works by Polish authors, while leaving the all-inclusive analysis for another publication.

For many years, the notion of map that functioned (and functions to some extent until now) in literature and common usage was similar to the concept of a map defined by M.-J. Kraak and F.J. Ormeling (1996) as "a graphic model of the spatial aspects of reality" or by N. Thrower (1996) as "a representation, usually on a plane surface, of all or part of the earth or some other body showing a group of features in terms of their relative size and position". And indeed, maps appeared only in such graphic form until the early 1990s and the above definition was then sufficient. But technological progress (particularly in informatics and information-communication technology, ICT) taking place in the following years, makes it necessary to take a fresh look also at the cartographic products. Subsequently, the evolving definition of a map is becoming increasingly universal and less tightly linked to the form of information communication. Premises for this can be found in many earlier cartographic publications (for example C. Board, L. Ratajski, J. Gołaski, A. Czerny).

For the majority of the public, internet is the primary source of information about almost any phenomenon, event, or person and among others, Wikipedia plays a particularly important role in this respect. Therefore, it is hard to avoid examining definitions circulating in cyberspace. In the English version of Wikipedia, we can find the following definition of a map (source: Wikipedia, Oct. 31 2016, https://en.wikipedia. org/wiki/Map): "A map is a symbolic depiction highlighting relationships between elements of some space, such as objects, regions, and themes". The most noteworthy part of this definition is its assertion that "a map is a symbolic depiction" because symbolic depictions are not limited to graphic representations - although such narrowing of the concept can still be encountered in common parlance.

The source of the above map definition expands later to clarify that "Many maps are static two-dimensional, geometrically accurate (or approximately accurate) representations of three-dimensional space, while others are dynamic or interactive, even three-dimensional. Although most commonly used to depict geography, maps may represent any space, real or imagined, without regard to context or scale; e.g., brain mapping, DNA mapping and extraterrestrial mapping". This definition then decisively departs from the restricted notion of a map as static, two-dimensional description of geographical space.

As mentioned above, the 10th ICA General Assembly in Barcelona in 1995 adopted the following definition: "A map is a symbolised representation of geographical reality, representing selected features or characteristics, resulting from the creative effort of its author's execution of choices, and is designed for use when spatial relationships are of primary relevance". This definition frames the concept of a map broadly, making it independent of technology 
available to cartographers at a particular time. It also notably uses phrases such as "a symbolised image of geographical reality" and "resulting from creative effort". Therefore, this map definition is no longer limited to the image on a plane, the image on a paper, or even a graphical representation. However, including the role of creative effort in the definition removes from its scope certain products of geoinformatics. For example, a satellite image or aerial photograph in its "raw" (unprocessed) form cannot be called a map given this definition.

A very universal in extent definition formulated by $C$. Board and included in the report of the ICA working group for the definition of cartography (1990) construes a map as "a presentation or abstraction of geographical reality. A tool for presentation of geographic information in a visual, digital or tactile way". In this particular instance, the author directly points out that the map's essence is determined by its function as a model rather than by the form of cartographic communication.

In this regard, J. Gołaski (1998) makes a particularly pertinent remark: "It seems that electronic tools have not created new structures, but only a new type of symbols and a new type of media carrying those symbols. Those symbols are not accessible to human senses but can be made visible by computer hardware and software".

Interesting reflections on the nature of a map and its resemblance to language presents also John Pickles (1992) by comparing map to the text consisting of interrelated words and relying on a system of symbols with its own syntax. In his approach, maps are the forms of symbolization governed by a set of conventions aimed to provide information needed to attain the understanding of space. Maps allow the user to gain insight into the character of space (location). An important concept in Pickles' considerations is the notion of cartographic communication, i.e., the message in specific context that must be properly decoded.

Much earlier ruminations on the concept of cartographic communication initiated by C. Board (1967), A. Koláčný (1969) and L. Ratajski (1972) have left a lasting imprint on cartography and contributed to the improved understanding of the function of maps. In the ICA dictionary of cartographic terms (1973), the concept of cartographic communication is defined as "the process of transmitting cartographic information". This definition was widely discussed in the Polish cartographic literature, mainly in terms of its wording (L. Ratajski 1978, J. Gołaski 1973, W. Grygorenko 1982, J. Gołaski 1984). According to W. Grygorenko (1982), Ratajski's criticism of that definition was among the reasons for the ICA Multilingual Dictionary of Technical Terms in Cartography adopting another definition of cartographic communication as "a system of information flow among the elements of reality - mapmaker - cartographic model of reality - map user - imagined reality".

A very interesting, comprehensive and extensive review of different perspectives on the definition of cartographic communication presents J. Ostrowski (1984) in his analysis of works by E. Imhof, E. Arnberger and I. Kretschmer, W. Bunge, J. Bertin and U. Freitag, L. Ratajski and C. Board, A. Aslanikashvili and K.A. Salistchev. Although diverse approaches to the problem of cartographic modelling competed throughout the history (cognitive versus communication approach), it can be said that cartographers have adopted the general premise of the "modelling nature of maps" far in the past. In this context, it is out of the question to overlook the fundamental work by $\mathrm{C}$. Board (1967) introducing the theme of perceiving map as a model to the literature and initiating the communication thread in cartographic research.

The concept of modelling is used in many contexts. The PWN "Dictionary of the Polish Language" indicates that modelling can be understood as:

1) giving something a suitable shape;

2 ) influencing the course or nature of something;

3) creating models of systems or physical phenomena for research purposes;

4) giving an appropriate shape to a work through various means of composition;

5 ) emphasizing the three-dimensional of something using colour, light, shadow, etc.

Cartographic modelling is primarily concerned with the first, third and fourth item on the list above. Worth quoting is also another simple and lucid definition featured in one of the Polish online encyclopaedias: "Modelling is an approximate rendering of the most important properties of the original. The primary objective of modelling in science is to simplify the comple- 
xity of reality in order to make it amenable to research processes" [1]. It is also worth mentioning a widely accessible definition derived from reflections compiled in the work of $\mathrm{N}$. Cartwright (1983) and I. Hacking (1983) and made available in Wikipedia:

"Scientific modelling is a scientific activity, the aim of which is to make a particular part or feature of the world easier to understand, define, quantify, visualize, or simulate by referencing it to existing and usually commonly accepted knowledge. It requires selecting and identifying relevant aspects of a situation in the real world and then using different types of models for different aims, such as conceptual models to better understand, operational models to operationalize, mathematical models to quantify, and graphical models to visualize the subject. Modelling is an essential and inseparable part of scientific activity, and many scientific disciplines".

The comprehensive overview and detailed analysis of all relevant definitions falls well beyond the scope of this paper. Having agreed with the definitions chosen and quoted above, the authors adopted them as a starting point of their own deliberations. At the outset, they have recognized cartographic modelling as one of the general types of modelling performed with an explicit goal of creating a map as specific model ascribed to cartography as a science and practical activity.

Defining concepts in science can be implemented in two main ways, as J. Gołaski maintained in the discussion on cartographic modelling many years ago (1984). The first one involves listing the properties of objects in question, while the second way facilitates acquisition of a given concept by providing another, similar concept that is already familiar to the recipient. The attempt to define cartographic modelling presented later in this article is based on the first approach'.

\section{Map as a model}

Understanding map as a specific model of space has been a subject of many studies in

\footnotetext{
1 The authors agree with the view presented by Gołaski (by no means an isolated opinion) that "definitions of the first type can play a creative role in science by explaining the essential features of the examined object, and the second type plays a role mostly in communication".
}

the last fifty years. Precursors of the modern approach to cartographic modelling included C. Board (1967) and G. Hake (1973), who distinguished between primary models resulting from direct observations of the reality, secondary models comprising cartographic representations or transformation of the primary models, and tertiary models signifying mental images of objects and phenomena shown on the map.

Map is one of many types of models of the space and therefore, its distinguishing properties are itemized in map definitions in order to determine its specific nature. In one of the first definitions, K.A. Salistchev (1967) defines map as a image-symbol model that emulating one or another aspect of the reality in a schematic (generalized) and visual form,.

Wide-reaching deliberations on the theme of map as a model are presented in the monograph by A. Czerny (1993). Resorting to the theory of relations, he puts forth a hypothesis that the cartographic model of reality (map) can be viewed as a system formed by a set of particular symbols with defined properties and remaining in specific relations to each other. Czerny's reflections have a universal character as long as provided that we narrow the concept of maps only to graphical models. After removing just this one restriction, the rest of his reflections would remain valid and could facilitate the broad treatment of a map as a spatial model communicated to the recipient in various forms.

In several publications, A. Makowski (2001, 2005a, b, c, 2006) stresses that map has three basic attributes: it is a model, a system and an image. In particular, he draws attention to the systemic nature of a map. It has characteristic properties of systems: fittingly selected members of the set and structure governing selection of elements based on the relations among them and their properties (A. Makowski 2001). Map as a model is the result of thought processes operating on concepts - particularly of abstraction and generalization - and first of all, performing cognitive functions.

In Makowski's proposals, map is "the model-image system and information entity that reflects practical time-space situations as areas of purposeful actions in the adopted reference system". In accordance with the described intention, the author's definition encompasses "topologically correct maps (mental maps in- 
cluding also maps for the blind and memory maps) as well as geometrically and topologically correct maps (e.g., representations of the content of digital data bases, paper maps, Internet maps)". What's worth attention is that also in those studies, the concept of image is not equated with graphics. It pertains primarily to mental images, or more precisely: mental images of space.

Taking these considerations into account, the following map definition was proposed in D. Gotlib (2011) study: "A map is a model of reality, showing the location and characteristics of selected objects and phenomena in relation to the Earth's surface, another celestial body or other objects, e.g. a building, the interiors of the human body, or the spatial relationships between objects or phenomena". At the same time, it was established that the model can apply to current, past, or future status as well as to represent changes over time. The model can be communicated to the recipient using various modalities: graphic, audible, textual, tactual. It can also be processed and analysed merely in digital form.

The above study has considered also two different schemes for developing the cartographic message: without and with the use of spatial databases. In either case, the subject-matter of cartographic communication is the model of space. Before digital technology became widely used in cartographic production, this model was rarely recorded in a standardized and formalized form (it often functioned exclusively in the mind or notes of the mapmaker). The only material reflection and clearest manifestation of the model was a completed cartographic product (e.g. a classic analogue map), becoming also the only form of cartographic communication reaching the recipient. In the most general terms, the introduction of spatial databases to cartographic practice technology has not changed fundamentally the idea of designing the cartographic communication - just like before, cartographic modelling must be carried out to develop an appropriate model of space (fig. 1).

The modelling process is supported by domain-specific (thematic) modelling ${ }^{2}$ (related to

\footnotetext{
2 The domain-modelling is understood here as the modelling process that is specific to other disciplines and branches of science. One example are procedures leading to the
}

the subject-matter of communication, eg. geological, meteorological or historical themes). Both types of modelling affect the way of processing the source data collected by various survey methods (most commonly the geodetic survey). Thanks to the spatial database and GIS technologies, the model created can be formalized and saving (materialized) it in strictly defined structures of numerical format (D. Gotlib 2011). Therefore, it is possible to communicate cartographic information to the recipients in various forms: from traditional paper printouts to various display visualizations (including video streaming), to informing by sound.

It should be noted that maps can be made accessible to the recipients using a variety of media: paper, plastic mass, computer screen, holographic projectors or digital records. Sometimes, the same map can be communicated and received by the user in various ways. Thus, classifying a process as part of cartographic modelling depends not on the form of cartographic communication but rather on the essence of the message, i.e. a set of features that distinguish the process from other processes of space modelling. What qualities should we then choose to conclude that we are dealing with the process of cartographic modelling?

In order to answer this question, the authors analysed a number of different representations of space found both in daily life and scientific

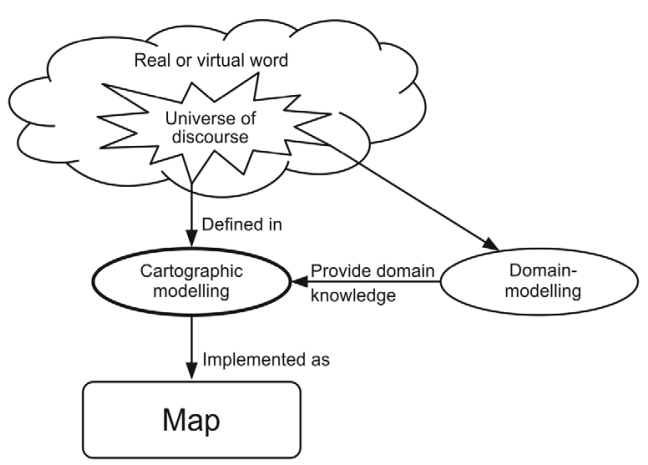

Fig. 1. From real or virtual world to the map

development of commonly used meteorological models. These can be used to obtain weather forecast for the selected field in e.g. $4 \times 4 \mathrm{~km}$. mesh, Based on such models, cartographer can use cartographic modelling to create weather maps in a variety of formats and versions. 
Tab. 1. Examples of spatial products used in this study along with information about the fulfillment of conditions associated with cartographic modelling

\begin{tabular}{|l|c|c|c|c|c|c|c|c|}
\hline \multicolumn{1}{|c|}{ Modelling feature / Product } & C1 & C2 & C3 & C4 & C5 & C6 & C7 & C8 \\
\hline Paper topographic map & 1 & 1 & 1 & 1 & 1 & 1 & 1 & 1 \\
\hline Electronic map in a navigation system & 1 & 1 & 1 & 1 & 1 & 1 & 1 & 1 \\
\hline Aerial or satellite orthophoto in the original version & 1 & 0 & 0 & 1 & 0 & 0 & 0 & 0 \\
\hline $\begin{array}{l}\text { Aerial or satellite orthophoto in the version supplemented } \\
\text { with the legend and geographic names ("orthophotomap" } \\
\text { or "image map") }\end{array}$ & 1 & 1 & 1 & 1 & 1 & 1 & 1 & 1 \\
\hline Cloud of laser scan dots stored in computer memory & 1 & 0 & 0 & 1 & 0 & 1 & 0 & 1 \\
\hline Model of the real world stored in a computer game & 1 & 1 & 1 & 1 & 1 & 1 & 1 & 1 \\
\hline Model of the fictional world stored in a computer game & 0 & 1 & 1 & 1 & 1 & 1 & 1 & 1 \\
\hline Diagram of an electrical device & 0 & 1 & 0 & 0 & 1 & 1 & 1 & 1 \\
\hline $\begin{array}{l}\text { Printed diagram of a circuit board pattern of an electronic } \\
\text { device }\end{array}$ & 0 & 1 & 1 & 1 & 0 & 1 & 1 & 1 \\
\hline Realistic painting of an urban landscape & 1 & 0 & 1 & 0 & 1 & 1 & 1 & 1 \\
\hline Abstract painting of space & 1 & 0 & 1 & 0 & 1 & 1 & 1 & 0 \\
\hline Architectural and construction building drawing & 0 & 1 & 1 & 1 & 1 & 1 & 1 & 1 \\
\hline Model of building interior stored in a spatial database & 1 & 1 & 1 & 1 & 1 & 1 & 1 & 1 \\
\hline
\end{tabular}

research. The list of analysed models/portraits of space is presented in table 1 and selected examples are shown in figure 2. Additionally, the analysis included also such products as sets of GIS vector data sets stored in a database, digital elevation models stored in various formats, globes, holographic terrain representations, diagrams of the car chassis, diagrams (models) of atoms, diagrammatic models of the biosphere, visualized mental maps and literary descriptions of selected areas.

This research aimed to seek common features among those analysed products that are viewed as typical cartographic representations and to check whether other products (such as diagrams of electrical devices or an abstract painting of urban space) posses similar or even identical features. If the response was affirmative, then search continued for properties permitting to distinguish them from cartographic representations. Next, an initial set of characteristics was formulated, the categorization process was performed for the entire set and results were evaluated. The process was carried out iteratively and results have been repeatedly subjected to discussion.
Within the framework of adopted methodology, the authors have identified eight properties (features of modelling) that must be met in the process of cartographic modelling:

C1. Portraying of space.

C2. Identifiability of types of objects and phenomena.

C3. Description of spatial relationships between objects.

C4. Localization in an applied reference system.

C5. Deliberate choice of a certain level of generalization compliant to the map's objective

C6. Symbolization based on knowledge.

C7. Aware authorship of the message.

C8. Explicitness of communication (conformity between intention and reception).

The authors propose to recognize as cartographic modelling only those processes that simultaneously meet all of the above conditions.

Portrayal of space $(\mathrm{C} 1)$ is understood here as describing a specific arrangement of objects or phenomena in the real or virtual world. A typical example is the process of constructing a topographic map depicting an existing piece of terrain. A similar situation takes place during creation of a navigation map in the computer 

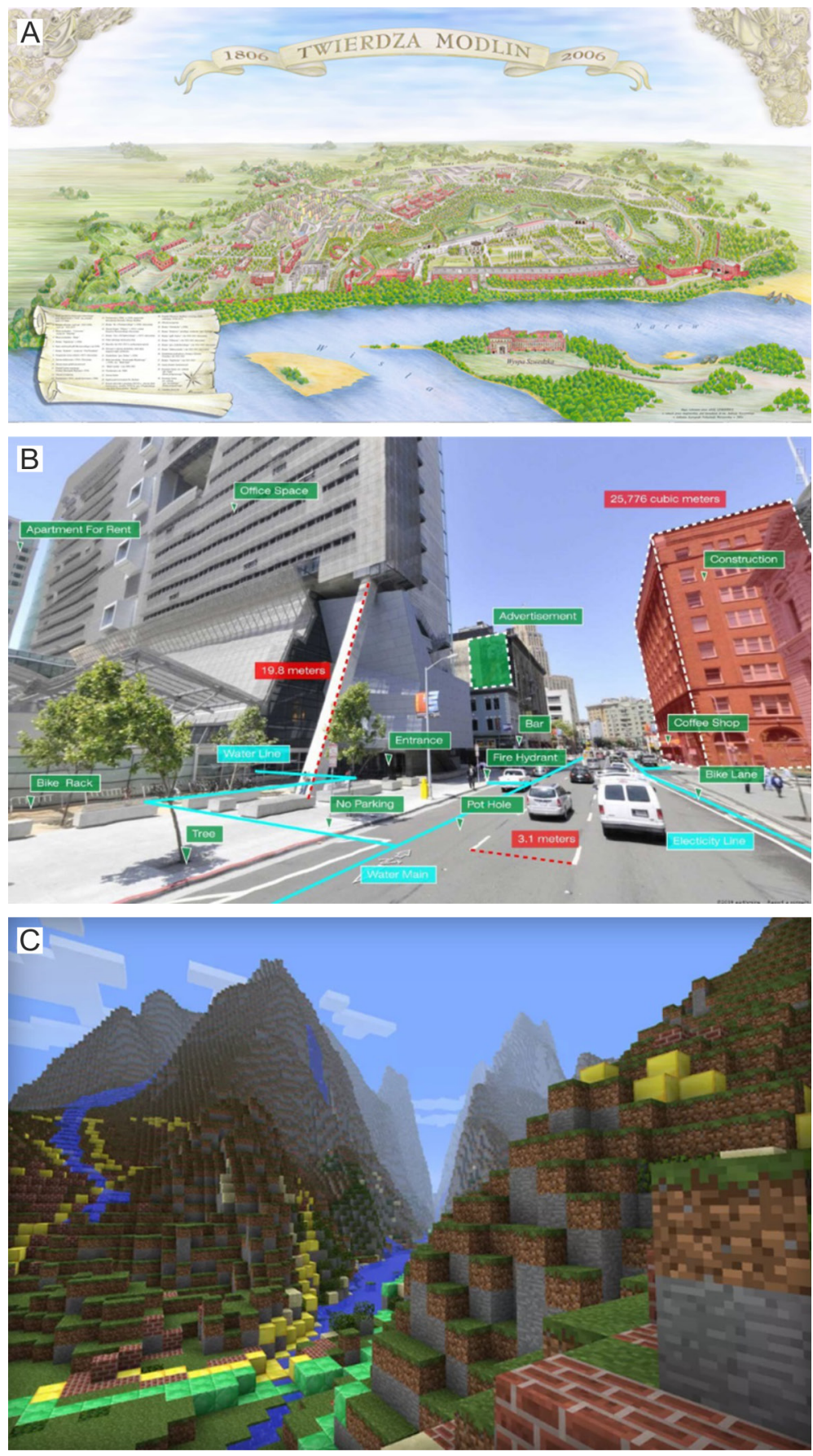

Fig. 2. Different ways of depicting space (selected examples analysed in the study): A - spatial model created manually in the form of a drawing (source: A. Lenkiewicz 2005, Faculty of Geodesy and Cartography Warsaw, University of Technology); B - visualization of the spatial model in the system of Virtual Reality (source: http://www. wired.com/); C - visualization of the spatial model in computer game Minecraft (source: minecraft-uk-main) 
game presenting the virtual world. In this context, the architectural/construction design of the building is just a template and its creation is not treated as cartographic modelling. But developing a plan (map) of a specific, already constructed building, meets condition $\mathrm{C} 1$.

A model developed in the course of cartographic modelling should facilitate identification of objects, as opposed to, e.g. the classic photography. The map user should be able to clearly determine, what kind of object or phenomenon is dealt with: industrial building, forest, tourist trail, the locus of coal deposits. This condition is marked in the proposed approach as $\mathrm{C} 2$.

In turn, condition C3 will be satisfied when it is possible to read from the model directly or indirectly (not just through deduction) the relationships between objects and phenomena, such as a building and a road, a settlement and monuments, etc. All kinds of relationships - metric, topological and directional - can be taken into consideration.

In contrast to other models describing spatial relationships, it is important for cartographic models to ensure an unambiguous frame of reference for the modelled objects and phenomena (C4). It should be stressed, however, that the defined reference system can be global as well as local. This may be a coordinate system or location described with help of geographic identifiers (e.g. names). Of key importance is the user's ability to obtain more or less precise information about location of specific objects instead of the typical for technical drawings unidentified members of a group of objects. A technical drawing of, e.g. a car may present spatial relationships between the position of engine and car axles but information is not specific to any particular automobile.

Another important property of cartographic modelling (C5) is generalization of spatially localized information, i.e. the adoption of one or several specific levels of generalization, customized to fit the product's purpose and perceptual capabilities of the recipient (receiver may be human or machine). For example, a satellite image of a given area does not meet condition C5 because it is generated automatically, with spatial resolution depending on the sensor used to generate the image rather than on the purposeful generalization effort on the part of product's creator.
A characteristic feature of many models of reality is the thoughtful use of a wide array of symbols (graphic, verbal, audible, binary code, etc.) that adequately suit the purpose and intent of the model and perceptive abilities of the recipient. Cartographic models are also subsumed in this group (condition C6), as opposed to physical models such as, e.g. a precisely-moulded wax figure.

Cartographic model is created in the process permeated with the subjectivity of its creator (condition C7), who works to realize the goal set to transmitting the information intended for a specific recipient. This does not mean that products generated in a fully automated manner do not meet this condition, because the authorship can be credited in such products at the design stage of an algorithm controlling the process of map creation.

Condition C8 (explicitness of communication) is necessary to guarantee the unambiguous interpretation (at the adopted level) by both the product's creator and its potential user. An abstract painting of a chosen vicinity does not meet this condition, although it may portray the space and can present certain spatial relations.

Table 1 lists spatial representations (portrayals of geographical space) considered in this study along with the assigned values of 1 (true) or 0 (false) indicating the presence of a given property (the condition in question is met or not, respectively).

The analysis results presented in table 1 indicate that representations generated in the process of cartographic modelling can include products such as:

- Paper topographic map;

- Electronic map in a navigation system;

- Model of the real world in a computer game;

- Aerial or satellite orthophoto in the version supplemented with the legend and geographic names ("orthophotomap" or "image map");

- Model of a building interior stored in a spatial database.

In the case of these products, all of the above features of cartographic modelling are then fulfilled. These representations are generated in the course of modelling process, which (in the authors' opinion) is typical of cartography and leads to the map creation. Of course, the analysed artefacts are only selected examples and each requires broader description. Here, description has been reduced to a bare minimum 
due to the limited scope of this publication. Many questions remain also when it comes to the further analysis and research. Among other issues, it is worth to address the question of the concept of "georepresentation" introduced by A.M. Berlant $(1985,1993)$ and utilized by many other authors.

In his deliberations, A.M. Berlant adopted a map definition that was very limited in scope but used most commonly in the final years of the twentieth century. After so many years, the approach proposed in A. Berlant's work should be verified from today's perspective and updated accordingly. For the question arises whether map should be classified only as one of the two-dimensional georepresentations? Perhaps this publication can make finding the answer to this question easier.

Another interesting research thread would be taking a look from cartographic perspective at spatial models used in computer games, electronic virtual tours in $3 \mathrm{D}$ and so on. The threshold between maps and other models of space is not always sharp and still requires an analysis of purpose and functionality of specific products. Among others, J. Gołaski (1998) pointed out this problem when analysing the so-called written and landscape painting-type cartographic primitives: "While the transition from the structure of written word to cartographic structure was a real revolution ${ }^{3}$, the threshold between landscape painting and map is not as sharp. A gradual transition from one structure to another is entirely possible". It is also noteworthy that in some cases of various models analysed in this study, the use of fuzzy logic ("largely fulfils", "barely fulfils", and so on) would be more convenient. But at this stage, the classical two-valued logic (true, false) was applied for pragmatic reasons and with the assumption of further research in this area.

\section{Summary and conclusions}

Delineation of sharp frontier line between cartographic modelling and other types of space modelling is probably not possible - and it does not seem necessary. Much more justifiable

\footnotetext{
$3 \mathrm{~J}$. Gołaski used this phrase in reference to the forming process of large-scale maps depicting great estates in Central Europe between the fifteenth and eighteenth century.
}

would be to classify models in terms of fuzzy sets, that is, determining that the model to a greater or lesser extent, belongs to a set of cartographic models. Fulfilment of the eight proposed conditions by a modelling process can likely pass it to the cartographic models, or models resulting from cartographic modelling. This is probably the first attempt aiming at such definition of the concept of cartographic modelling. Using it in the process of portraying, the cartographic modelling itself is the essence of the cartography. The result of cartographic modelling is usually a map. But that is understood much more broadly than in the past - as one of the models meet certain terms defined in of the theory of cartography. However, there are cases where the cartographic modelling does not necessarily lead to the creation of the map, but only to achieve some desired information. But this thread extends beyond the scope of this study.

The attempt undertaken in this study to define the properties of cartographic modelling understood in this particular way is just the beginning of further analysis and theoretical considerations. In the authors' opinion, it is advisable to initiate and subsequently deepen the research and discussion on this topic. This is because such activities can have substantial impact on the determination of identity of cartography, and on its connections with other areas of scientific activity and map production. The number of currently created products with typical characteristics of cartographic representations is greater than ever. These include all kinds of classic analogue maps as well as all sorts of innovative electronic products. In the latter case, however, it is often forgotten that they are created in the process of cartographic modelling and using well-known cartographic methods. The resulting new products are often just the new versions of maps that have been created for centuries.

Their essence does not change. In the manner well-though through by their authors, they portray space for a purpose of localizing objects and phenomena as well as providing information about the apparent spatial relations. They differ from the classical maps only in terms of technology used in their production, the technology of their use of technology and the technologies applied in the process of cartographic communication. These technologies, however, 
are only of secondary importance from the viewpoint of cartography. In the author's opinion, what matters is a long-held view that map is an ordered informational structure shaped through the many years of experience and research in the domain of cartography. And this understanding allows us to look at the future of cartography with great optimism.

\section{Literature}

Berlant A.M., 1985, Integracija kartografičeskogo i aérokosmičeskogo metodov. „Geografija i prirodnye resursy" No. 4.

Berlant A.M., 1993, Geoprzedstawienia i geoikonika. „Polski Przegląd Kartograficzny” T. 25, nr 3, pp. 105-113.

Board C., 1967, Maps as a models. In: Models in Geography. Eds. R.J. Chorley and P. Haggett. London: Methuen, pp. 671-725.

Board C., 1990, Report of the Working Group for Cartographic Definitions, International Cartographic Association.

Cartwright N., 1983, How the Laws of Physics Lie. Oxford: Oxford University Press.

Czerny A., 1993, Cartographic model of reality. Structure and properties. „Geographical Studies”, Special Issue No. 7, Ossolineum, 77 pp.

Gołaski J., 1973, Funkcjonalno strukturalna koncepcja pojęcia mapy. „Polski Przegląd Kartograficzny” T. 5, nr 1, pp. 7-12.

Gołaski J., 1984, Wokół definicji przekazu kartograficznego. „Polski Przegląd Kartograficzny” T.16, nr 4, pp. 172-176.

Gołaski J., 1998, Mapy pomiędzy pismem, obrazem i elektronicznymi środkami informacji, „Polski Przegląd Kartograficzny" T. 30, nr 4, pp. 251-259.

Gotlib D., 2011, Metodyka prezentacji kartograficznych w mobilnych systemach lokalizacyjnych $i$ nawigacyjnych. „Prace Naukowe Politechniki Warszawskiej-Geodezja" Z. 48, 158 pp.

Grygorenko W., 1982, Cybernetyczny model przekazu kartograficznego. „Polski Przegląd Kartograficzny” T. 14, nr 2, pp. 67-78.

Hacking I, 1983, Representing and Intervening. Introductory Topics in the Philosophy of Natural Science. Cambridge: Cambridge University Press.

Hake G., 1973, Kartographie und Kommunikation. „Kartographische Nachrichten” Bd. 23, pp. 137-148.

Kraak, M.-J., Ormeling F.J., 1996, Cartography, the Visualization of Spatial Data. London: Addison Wesley Longman.

Koláčný A., 1969, Cartographic information: A fundamental concept and term in modern cartography. "The Cartographic Journal" Vol. 6, no. 1, pp. 47-49. Makowski A., 2001, Trójdzielna jedność mapy na tle idei systemu informacii przestrzennej. „Polski Przegląd Kartograficzny" T. 33, nr 1, pp. 38-42.

Makowski A., 2005a, Ontogeneza mapy. In: System informacji topograficznej kraju. Ed. A. Makowski. Warszawa: Oficyna Wydawnicza Politechniki Warszawskiej, pp. 19-41.

Makowski A., 2005b, Pojęcie mapy. In: System informacji topograficznej kraju. Ed. A. Makowski. Warszawa: Oficyna Wydawnicza Politechniki Warszawskiej, pp. 42-48.

Makowski A., 2005c, Spór o mapę. Wprowadzenie do pojęcia mapy. In: Projektowanie i redakcja map. Eds. W. Pawlak, W. Spallek. Wrocław: Uniwersytet Wrocławski, pp. 65-72.

Makowski A., 2006, Definicja kartografii (propozycja). In: Świat techniki w kartografii. Eds. W. Pawlak, W. Spallek. Wrocław: Uniwersytet Wrocławski, pp. 40-44.

Multilingual Dictionary of Technical Terms in Cartography, 1973, International Cartographic Association, Commission II. Definition, Classification and Standardization of Technical Terms in Cartography. Wiesbaden: F. Steiner Verlag, 473 pp.

Ostrowski J., 1984, Podstawowe koncepcje teoretyczne i stanowiska metodologiczne we współczesnej kartografii. „Polski Przegląd Kartograficzny” T. 16, nr 4, pp. 157-172.

Pickles J., 1992, Text, hermeneutics and propaganda maps. In: Writing Worlds: Discourse and Metaphor in the Representation of Landscape. Eds. Barns and J.S. Duncan. London: Routledge, 1992.

Ratajski L., 1972, Struktura kartologii i jej problematyka badawcza. „Polski Przegląd Kartograficzny” T. 4, nr 2 , s. 49-55.

Salistchev K.A., 1967, Einführung in die Kartographie. Bd. 1, Gotha-Leipzig: VEB Hermann Haack.

Thrower N., 1996, Maps and Civilization. Cartography in Society. Chicago: University of Chicago Press.

\section{Internet sources}

[1] ICA - http://icaci.org/mission/

[2] https://en.wikipedia.org/wiki/Map

[3] https://en.wikipedia.org/wiki/scientific_modelling

[4] Portal Wiedzy Onet.Wiem - http://portalwiedzy. onet.pl/65000, modelowanie, haslo.html 